\title{
THE EFFECT OF REPEATED TESTING ON THE MAXIMUM BREATHING CAPACITY IN NORMAL SUBJECTS \\ BY
}

\author{
JOHN FRIEND \\ From the Middlesex Hospital, London
}

(RECEIVED FOR PUBLICATION JUNE 7, 1955)

The maximum breathing capacity (M.B.C.) test (Hermannsen, 1933) may be used as an index of the ventilatory function of the lungs not only on one occasion but also, when the test is repeated at intervals, as an objective assessment of the progress of disease and of the effect of treatment upon it.

Although there have been some reports of the effect of repeated testing of the M.B.C. on one day, there appears to have been no study of the influence of learning on the M.B.C. when the test is made at intervals over a period of time.

There has been difference of opinion about the effect of learning on the M.B.C. when tested on one occasion. Gray, Barnum, Matheson, and Spies (1950) found an improvement of $12 \%$ between the first and second tests, and of $4 \%$ between the second and third tests, performed by healthy young people. After this no improvement occurred. Gilson and Hugh-Jones (1949), however, recorded no such improvement of M.B.C. in 17 patients.

This paper reports a re-examination of the presence of a learning factor in the acute experiment and an investigation of the effect on the M.B.C. of its repeated performance over a period of time.

\section{MeTHODS}

Thirty-five male medical students were studied. Their mean age was 23.1 years, range 19-31 years. None had suffered from any heart or lung disease or made any complaint of breathlessness on exertion or of cough. The subjects were volunteers and so cannot be considered truly representative of their selected age, sex, and social group.

The subjects stood to perform the tests with a spirometer of the type described by Bernstein, D'Silva, and Mendel (1952). A mouthpiece and noseclip were used. The recording drum was started 4 breaths after the beginning of hyperventilation and a 15-second period of maximum breathing was then recorded, timing being made with a stop-watch. The volume of each breath was measured on the tracing. The maximum breathing capacity is expressed in this paper as litres per minute, corrected to $37^{\circ} \mathrm{C}$.

An interval of two minutes was allowed between each test and the next. The subjects were asked, at their first test only, to "breathe as deeply and as quickly as possible, that is hyperventilate to the best of your ability," and were directed, if necessary, to increase their respiratory rate so that it exceeded 70 per minute. With all other tests they were given no instruction, demonstration, or exhortation to improve their performance and did the tests then as they thought fit. They were given no indication of the object of the investigation and were not told the result of any test.

The frequency and number of tests made were as follows:

(1) Subjects 1-10 each did a set of 10 tests on the same day.

(2) Subjects 11-15 did a set of three tests each day for five consecutive days.

(3) Subjects 16-35 did three tests each on one day of each of five consecutive weeks. These 20 students were divided into four equal groups. To avoid any possible effect of a change in weather on the maximum breathing capacity (testing started in mid-October, 1954), only one group was tested in the first week. In each week after this an additional group was tested. The results considered are those of the first five weeks of each group's tests.

(4) All 35 subjects were tested again (one set of three tests) three months after their last test in one of the above groups.

The mean results reported for groups of subjects have been calculated from the largest of the three tests made by the individual subjects.

\section{Results}

(1) First Set of Three Tests.-The first three tests made by each of the 35 subjects have been considered. The mean results of these tests were 
$177.0,188.5$, and 182.5 litres per minute respectively. A t test showed that the mean result of the second test was significantly larger than those of the first and third tests $(t=3.15, P=0.01-0.001$, and $\mathrm{t}=2.70, \mathrm{P}=0.02-0.01$ respectively). Analysis of variance of these tests gave a coefficient of variation of $7.5 \%$.

The mean of the maximal results from each subject was 194.9 litres per minute $($ S.D. $=30.4)$. The maximum result was produced in the first test by nine subjects, in the second test by 16 , and in the third test by the remaining 10 subjects.

(2) A SET OF 10 Tests. - The mean of these 100 tests was 175 litres. The mean results of the 10 successive tests were $166,177,168,179,178,182$, $180,182,171$, and 167 litres per minute.

Analysis of variance showed a significant variation between the tests and yielded a coefficient of variation of $6.2 \%$.

The means of the fourth to eighth tests exceeded that of the second test by up to 5 litres per minute. However, $t$ tests showed no significant differences between the mean result of the second test and these larger results following it $(P=>0.1$ in each case).

(3) Three Tests Daily for Five Days.-The mean results of these tests were 208, 222, 215, 220, and 222 litres per minute.

The mean result on the second day was significantly greater than that of the first day $(P=$ $<0.001$ ). Analysis of variance of the results over the second to fifth days showed, however, an insignificant variation $(P=>0.2)$.

(4) Three Tests Once Weekly for Five WEEKS.-Mean results of these tests were 199, 204, 207, 210, and 205 litres per minute.

Analysis of variance showed an insignificant change in these results $(P=0.2-0.05)$ and a co- efficient of variation of $6.7 \%$. A $t$ test between the first and fourth means showed no significant difference $(P=0.1-0.05)$.

(5) Three Tests Made After Interval of THREE MonTHS.-The mean results for all 35 subjects was 199.0 litres per minute. This did not differ significantly from the mean of the first set of three tests (194.9 litres per minute, $P=>0.1$ on $t$ test).

For the 20 subjects who were tested weekly for five weeks, the mean result in the fifth week of testing was 205.5 litres per minute. A t test showed that this mean was not significantly different from the mean result of the tests made three months later (204.8 litres per minute, $P=>0.1$ ).

\section{SUMMARY}

The effect of repeated testing upon the maximum breathing capacity has been examined in 35 healthy young adult males.

When the M.B.C. was tested repeatedly on one occasion there was a significant improvement between the first and second tests only. Thereafter there was no significant improvement up to the tenth test.

Daily tests showed an improvement between the first and second days, but none occurred after this.

Weekly tests demonstrated no improvement over a period of five weeks.

This work was started during the tenure of the Saltwell Research Scholarship of the Royal College of Physicians. I wish to thank Dr. D. D. Reid for his advice on the planning of the experiment and the students who co-operated in the tests.

\section{REFERENCES}

Bernstein, L. D'Silva, J. L., and Mendel, D. (1952). Thorax, 7, 255 Bernstein, L., D'Silva, J. L., and Pes, (1949). Clin. Sci., 7, 185.

Gray, J. S., Barnum, D. R., Matheson, H. W., and Spies, S. N. (1950). J. clin. Invest., 29, 677.

Hermannsen, J. (1933). Z. ges. exp. Med., 90, 130 